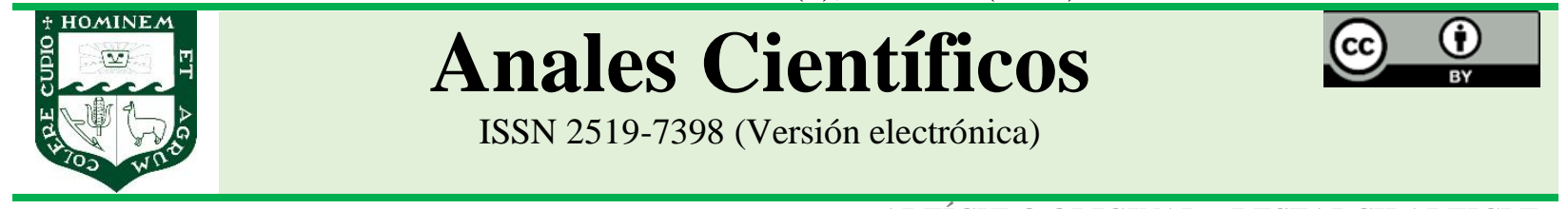

ARTÍCULO ORIGINAL - RESEARCH ARTICLE http://dx.doi.org/10.21704/ac.v82i1.1751

\title{
HALLAZGOS HISTOPATOLÓGICOS, ETIOLOGÍA Y PREVALENCIA DE LA "CASPA" EN VICUÑAS (Vicugna vicugna mensalis) EN LAS ZONAS DE AMORTIGUAMIENTO DE LA RESERVA NACIONAL DE PAMPA GALERAS
}

\author{
The histopathological findings, etiology and prevalence of the dandruff" in vicuñas \\ (Vicugna vicugna mensalis) in the buffer zones of the Pampa Galeras National Reserve
}

\author{
María Flores ${ }^{1}$; Wilder Trejo ${ }^{2}$; Gloria Palacios ${ }^{2 *}$ (1) \\ ${ }^{1}$ Facultad de Zootecnia, Universidad Nacional Agraria La Molina, La Molina, 15024, Lima, Perú. \\ *E-mail: gpalacios@ lamolina.edu.pe
}

Recibido: 26/06/2020; Aceptado: 25/04/2021; Publicado: 31/08/2021

\begin{abstract}
The objective of this study was to recognize the histopathological findings, to identify the possible agent etiological and to determine the prevalence of the "dandruff" in vicunas (Vicugna vicugna mensalis) in the buffer zones of the Pampa Galeras National Reserve Bárbara D'achille in Lucanas Rural Community- Ayacucho. Biopsies were taken from the rib region of sixty vicuñas among males and females, ages of youth and adults, which presented "dandruff" in a initial level, obtained from a total of 842 captures vicuñas. The samples were placed in $10 \%$ formalin, then were processed by the paraffin inclusion technique and coloured with H. - E., Gram coloration and PAS coloration. The results indicated that the prevalence rate of the dandruff in vicuñas was $9.03 \%$; the most affected population was adult females $(13,9 \%)$, young female $(13,2 \%)$ and young male $(8,2 \%)$. All the skin samples had hyperkeratosis in the córneous layer with parakeratosis $(86,7 \%)$ and orthokeratosis $(13,3 \%)$; also, was found the presence of acanthosis in the germinative layer of the epidermis. There was no evidence of fungal infections, parasites and/or bacteria. The histopathological results were compatible with nutritional deficient such as protein, fatty acids, vitamin A, zinc and copper. The most affected group was the vicuñas with the most nutritional requirements, such as vicuñas in growing and reproductive states. These results suggest that over grazzing native pasture is not enough to cover the nutritional requirements of these animals.
\end{abstract}

Keywords: Dandruff; Vicugna; Pampa Galeras

\section{RESUMEN}

El objetivo del presente estudio fue reconocer los hallazgos histopatológicos, identificar al posible agente etiológico y determinar la prevalencia de la "caspa" en vicuñas (Vicugna vicugna mensalis) en la zona de amortiguamiento de la Reserva Nacional de Pampa Galeras Bárbara D'achille ubicado en la Comunidad Campesina de Lucanas Ayacucho; que viene mermando la producción de fibra de vicuña. Se obtuvieron biopsias de la región costillar de sesenta vicuñas entre hembras y machos, de edades juveniles y adultos, que presentaron "caspa" en un nivel inicial obtenidas de un total de 842 vicuñas capturadas. Las muestras fueron colocadas en formol al $10 \%$ y luego procesadas por la técnica de inclusión en parafina y coloreadas con H.- E., con GRAM y P.A.S. Los resultados indicaron que la tasa de prevalencia de caspa en vicuñas es de $9,0 \%$; siendo los más afectados las hembras adultas $(13,9 \%)$, hembras juveniles $(13,2 \%)$ y machos juveniles $(8,2 \%)$. Todas las muestras de piel presentaron 
hiperqueratosis en el estrato córneo, con cuadros de paraqueratosis $(86,7 \%)$ y ortoqueratosis $(13,3 \%)$; además de un $100 \%$ de acantosis a nivel de la capa germinativa de la epidermis. No se encontró indicios de infecciones por hongos, parásitos y/o bacterias. Los hallazgos histopatológicos son compatibles con deficiencias nutricionales; tales como proteínas, ácidos grasos, vitamina A, zinc y cobre; y los más afectados son las vicuñas de mayores exigencias nutricionales, tal como ocurre durante el crecimiento y etapa reproductiva. Se sugiere que la sobre pastoreada pradera nativa no estaría cubriendo las necesidades nutricionales de estos animales.

Palabras clave: caspa; vicuña; Pampa Galeras

Forma de citar el artículo (Formato APA):

Flores, M.; Trejo, W. \& Palacios, G. (2021). Hallazgos histopatológicos, etiología y prevalencia de la "caspa" en vicuñas (Vicugna vicugna mensalis) en las zonas de amortiguamiento de la Reserva Nacional de Pampa Galeras. Anales Científicos. 82(1), 162-170. http://dx.doi.org/10.21704/ac.v82i1.1751

Autor de correspondencia (*): Gloria Palacios. Email: gpalacios@lamolina.edu.pe

(C) Los autores. Publicado por la Universidad Nacional Agraria La Molina.

This is an open access article under the CC BY

\section{INTRODUCCIÓN}

La vicuña (Vicugna vicugna mensalis) es una de las especies animales silvestres más codiciadas, ya que posee una de las fibras más finas de origen animal. La misma que es antialérgica, natural, de mayor poder aislante y sobre todo suave, con $100 \%$ de confort (CONACS, 2007); lo que hace que la fibra sea muy apreciada por la industria textil, superando en el año 2005 los US \$ 500 por $\mathrm{kg}$ de fibra descardada (Brack, 2010) y en la actualidad, el Perú ocupa el primer lugar a nivel mundial en la población de vicuñas con más del $65 \%$ de las vicuñas del mundo, encontrándose la mayor población de vicuñas en el Perú en la Reserva Nacional de Pampa Galeras- Comunidad Campesina de Lucanas-Ayacucho, lugar de donde se realiza el repoblamiento a otras zonas y logra ingresos por la venta de la fibra de US\$ 350000 al año sin que ello signifique un manejo eficiente de la vicuña (Trejo, 2013). Esto lo hace ser una población económicamente atractiva, que podrán en el futuro defender la sustentabilidad del uso de los recursos naturales y la rentabilidad de la vicuña como población de camélidos silvestres y, por otro lado, desde el punto de vista social, económico, ecológico y estratégico; es sin duda la base fundamental para el desarrollo de los pobladores altoandinos del Perú.

La piel de la vicuña como de cualquier mamífero representa la barrera anatómica y fisiológica entre el medio interno del animal y el medio externo. Previene la pérdida de agua, evita el ingreso de agentes físicos, químicos y biológicos. Regula la temperatura a través de diversas formas, como el riego sanguíneo cutáneo, la capa de pelo y la función secretora que cumple por intermedio de la secreción de sus glándulas sudoríparas y sebáceas y una función de producción de fibras por intermedio de sus folículos (Lacolla y col, 2001).

La piel presenta tres capas (epidermis, dermis o corium e hipodermis); siendo la epidermis el $1 \%$ del total de la piel (Rodriguez, 1985), está constituida por el estrato córneo que es la capa superficial formada por escamas córneas (Bustinza, 2001; Alzola, 2002) unidas estrechamente entre sí por apéndices inter-membrana llamados desmosomas entre lo que se encuentra el cemento intercelular formado por lípidos y presencia de abundante citoqueratina que se une a los desmosomas constituyendo una red sólida elástica (Palomino, 2001) y que sin embargo puede sufrir cambios patológicos por defecto o exceso (Gázquez, 1991).

El estrato granuloso, formado por células planas, nucleadas, con citoplasma plegado a la superficie y con presencia de granos de queratohialina (Bustinza, 2001), que no están rodeados por una membrana y formaran el material citoplasmático interfilamentoso del estrato córneo (Junqueira y Carneiro, 2000), pero forman una proteína agregante de filamentos llamada profilagrina y las proteínas de refuerzo de membrana que pasarán al estrato córneo (Palomino, 2001); el estrato espinoso cuyos núcleos son algo picnóticos, las células superficiales aplanadas y las profundas son poliédricas con cromatina laxa (Bustinza, 2001; Alzola, 2002); y finalmente, el estrato basal que presenta una intensa actividad mitótica y contiene filamentos de queratina que van 
en aumento conforme las células se diferencian y avanzan a la capa córnea (Junqueira y Carneiro, 2000).

Por otro lado, los nutrientes relacionados con la integridad de la piel son las proteínas, los ácidos grasos, la vitamina A, el zinc y el cobre. Los lípidos y la proteína rica en arginina son necesarios para la formación de una capa córnea funcional dándole resistencia y flexibilidad (Palomino, 2001). La vitamina A, interviene en la síntesis de glucoproteínas que contribuyen a la integridad del tejido epitelial en todas las cavidades del cuerpo; además penetra en la membrana y en óptimos niveles actúa como un agente ligante entre la proteína y el lípido dando estabilidad a la membrana y facilitando la permeabilidad celular y su deficiencia provoca alteraciones cutáneas que se manifiestan con una hiperqueratosis en la piel volviéndose áspera, seca con escamas, también causa pérdida de apetito, pérdida de peso, alteración de la audición, gusto y olfato (Mc. Dowell, 1989).

El zinc, juega un rol importante en: la formación del tejido epitelial, síntesis del colágeno y los ácidos nucleicos y en la regeneración de las células epiteliales de la piel para la cicatrización (Mc. Dowell, 1992) y su deficiencia provoca lesiones de paraqueratosis, engrosamiento

$\mathrm{o}$
hiperqueratinización con degeneración nuclear total de las células epiteliales de la piel. La deficiencia de zinc reduce la síntesis de DNA, RNA y proteínas, y por lo tanto, la división celular, afecta el crecimiento y la reparación celular (Radostits y col., 2000). El cobre, cumple funciones importantes en el metabolismo lipídico, demostrando su función en la actividad de desaturasas involucradas en la producción de ácidos grasos insaturados y precursores eicosanoides (Jenkins y Kramer, 1989); así como participa en el desarrollo del tejido conectivo, la mielinización de la médula espinal, la pigmentación de los tejidos, y en la síntesis de queratina; donde el cobre es requerido para incorporar los grupos disulfuro (Mc. Dowell, 1989).

Sin embargo, en los últimos años se ha encontrado en la población de vicuñas presencia de lo denominado comúnmente como "caspa", que afecta a la fibra de vicuñas esquilables dificultando el procesamiento textil de la misma y que en casos avanzados afecta visiblemente a la piel de la vicuña. A ello se suma la incapacidad de poder prever la presentación de este problema desde cómo prevenirlo hasta controlarlo y curarlo (Cotrina, 2009); ya que la "caspa" es únicamente identificable durante la actividad del chaccu y a la fecha no se cuenta con a información suficiente acerca del agente etiológico del problema ni cómo se distribuye el problema en la población de vicuñas.

En ese sentido, el presente trabajo tiene por objetivos reconocer los hallazgos histopatológicos, identificar al posible agente etiológico y determinar la prevalencia de la caspa en vicuñas en la zona de amortiguamiento de la Reserva Nacional de Pampa Galeras - Bárbara D’achille.

\section{MATERIALES Y MÉTODOS}

El estudio fue realizado entre junio y agosto del 2010, aprovechando los chaccus realizados en Ccanccollay, Ruspasccahuasi, Ccalahuaycco y Casablanca de la zons de amortiguamiento de La Reserva Nacional de Pampa Galera - Bárbara D'achille, perteneciente a la Comunidad Campesina de Lucanas-Ayacucho, localizada en la cadena occidental de los Andes (14\%42' LS y $74^{\circ} \mathrm{LO}$ de Greenwich) a 3900 m.s.n.m.

Todas las vicuñas fueron revisadas y se contabilizó las afectadas con "caspa", según sexo y edad. Se muestreo la piel sólo de aquellos animales que mostraron "caspa" a nivel inicial. Considerado como tal, a aquellos casos en que se presenta caspa entre la piel y la base de la fibra, y que a diferencia de los otros tipos de "caspa" no se aprecia visualmente lesión en la piel. De esta manera, se buscó descartar la presentación de lesiones secundarias al problema de "caspa".

Las muestras de piel fueron procesadas y sus respectivos cortes histológicos evaluados en el laboratorio del Programa de Investigación y Proyección Social de Ovinos y Camélidos Americanos (POCA) de la Universidad Nacional Agraria La Molina. 


\section{Obtención de las muestras y su Procesamiento}

Las vicuñas capturadas fueron revisadas en el corral de clasificación, contabilizando la totalidad de animales afectados con caspa y sólo se muestreo a las 60 vicuñas afectadas con "caspa" a nivel inicial, entre las que había 34 hembras adultas, 14 hembras juveniles, 8 machos juveniles y 4 machos adultos. A todos ellos se les extrajo una muestra de piel de la región costillar. Para ello, primero se realizó el corte de fibra con una tijera, seguido de rasurar la fibra restante y luego se tomó la biopsia de piel de $1 \mathrm{~cm}^{2}$. Las biopsias fueron extraídas con la ayuda de una pinza de disección diente de ratón y bisturí. Las heridas ocasionadas fueron tratadas con yodo, curabichera y cicatrizante como antiséptico.

La biopsia de piel obtenida se depositó en un frasco de vidrio de boca ancha con tapa rosca que contenía una solución fijadora de formol al 10\%. Los frascos fueron rotulados e identificados y luego trasladados al laboratorio.

En el laboratorio las muestras de piel fijadas en formol al $10 \%$ fueron lavadas en agua durante 20 minutos y luego deshidratadas con diferentes niveles de alcohol y Neo cler o xilol. Posteriormente, se procedió a la impregnación e inclusión en parafina en moldes de leuckhart, donde se dejó enfriar hasta que se solidifique a $-5^{\circ} \mathrm{C}$. Una vez solidificado, se procedió al corte histológico con micrótomo a un espesor de 4 micras y montaje en láminas. Para el montaje, los cortes histológicos se extendieron en un líquido atemperado a $50^{\circ} \mathrm{C}$ y recogidos en las láminas portaobjeto, para pasar por media hora al secador de láminas a $60^{\circ} \mathrm{C}$ de temperatura.

Cada muestra de piel se trabajó por triplicado para recibir cada una tinción diferente y cada lámina contenía 3 a 4 cortes histológicos. Es así que, por cada corte de piel: la primera lámina fue coloreada con Hematoxilina-eosina (H-E), para la observación de hallazgos histopatológicos y descarte de ácaros; la segunda lámina recibió la tinción con ácido per iódico de Schiff (P.A.S.), para el descarte de hongos y la tercera lámina se trabajó con tinción Gram, para realizar una diferenciación bacteriana (Alzola, 2001). Luego de la coloración pasaron por la aclaración con Neo cler y secaron a temperatura ambiente para finalmente realizar el montaje con Neo mount con la laminilla.

\section{Parámetros para evaluar}

La prevalencia se determinó a través de la Fórmula 1 .

$$
\text { Prevalencia }=\frac{\text { № de afectados }}{\text { № de individuos totales }}
$$

\section{Hallazgos histológicos}

Los cortes histológicos de piel fueron observados en aumentos de 100X y 400X para el descarte de la presencia de algún agente etiológico para la evaluación histopatológica del tejido epitelial.

Se revisaron todas las láminas con tinción PAS, GRAM y H-E para reconocer la presencia de hongos, bacterias y/o parásitos. Con tinción PAS, la presencia de hongos es positiva siempre que se observa cuerpos de color rojo a rosas intensos. Con tinción GRAM, la presencia de bacterias Gram (+) se visualizará de color morado o azul y las bacterias Gram (-) se visualizarán de color rosa o rojo. Con la tinción H-E se evaluó la presencia de ácaros y se observó las estructuras histológicas de la piel de los animales afectados.

Hiperqueratosis. En los daños causados se determinó ortoqueratosis y/o paraqueratosis; evaluándose el grado de desprendimiento de la capa córnea: (+): Normal; (++): Regular; y, $(+++)$ : Abundante.

Acantosis. Se evaluó el grado de hiperplasia presente en la capa basal o germinativa en 3 niveles: Nivel 1: Hiperplasia leve; Nivel 2: Hiperplasia moderada; y, Nivel 3: Hiperplasia abundante

Los resultados obtenidos de prevalencia y los daños histopatológicos de hiperqueratosis y acantosis fueron sometidos a un análisis de X2 cuadrado para establecer comparaciones entre sexo y edad, según el nivel de daño presentado. 


\section{RESULTADOS Y DISCUSIÓN}

\section{Prevalencia}

De las 842 vicuñas capturadas se encontró que el 367 fueron hembras adultas, 129 hembras juveniles, 261 machos adultos y 85 machos juveniles; encontrándose 76 vicuñas afectadas por "caspa", repartidas en 51 hembras adultas, 17 hembras juveniles, un macho adulto y 7 machos juveniles. Esto dio una prevalencia del 9\%; sin embargo, al determinar la prevalencia de la enfermedad según su sexo y edad (Tabla 2) se tiene que la enfermedad es estadísticamente más prevalente en hembras $(13,7 \%)$ que en machos (2,3\%), no existiendo diferencia estadística entre las hembras juveniles $(13.2 \%)$ con las hembras adultas $(13,9 \%)$ y por otro lado, la enfermedad afecta más a los machos juveniles $(8,2 \%)$ que a los machos adultos $(0,4 \%)$.
Hay que considerar que la población de vicuñas es manejada en condiciones de silvestría, diferenciándose este sistema por el uso de módulos de uso sustentable de la vicuña, consistente en cercos ganaderos de entre 1000 a 2000 hectáreas de extensión. El sistema aplicado no interfiere con el desarrollo natural de la población, desarrollo reproductivo de los grupos, no se brinda ninguna suplementación nutricional. A ello, se suma que la "caspa" en vicuñas se presenta más en hembras, sea que están en crecimiento y/o edad reproductiva y en segundo lugar en machos en crecimiento. Esto sugiere que la afección de "caspa" afecta primordialmente a la población de mayores exigencias nutricionales.

Tabla 2. Prevalencia de "caspa" en la población de vicuñas en zonas de amortiguamiento de la R.N.P. Galeras.

\begin{tabular}{|c|c|c|c|c|c|c|}
\hline \multirow[t]{2}{*}{ Sexo/ Edad } & \multicolumn{4}{|c|}{$\begin{array}{c}\text { Zonas de amortiguamiento } \\
\mathrm{N}^{\mathrm{o}} \text { afectados con caspa/ } / \mathrm{N}^{\circ} \text { capturados }\end{array}$} & \multirow{2}{*}{$\begin{array}{l}\text { Población } \\
\text { total } \\
\text { capturada }\end{array}$} & \multirow{2}{*}{$\begin{array}{l}\text { Prevalencia } \\
\text { de la } \\
\text { "caspa" }\end{array}$} \\
\hline & Ccanccollay & Rupasccahuasi & Ccalahuaycco & Casablanca & & \\
\hline q adultas & $28 / 245$ & $10 / 81$ & $6 / 33$ & $7 / 8$ & $43,6 \%$ & $13,9 \%$ a \\
\hline o juveniles & $9 / 89$ & $3 / 24$ & $4 / 13$ & $1 / 3$ & $15,3 \%$ & $13,2 \% \mathrm{a}$ \\
\hline Total 9 & $37 / 334$ & $13 / 105$ & $10 / 46$ & $8 / 11$ & $58,9 \%$ & $13,7 \%$ a \\
\hline odultos & $1 / 171$ & $0 / 55$ & $0 / 31$ & $0 / 4$ & $31,0 \%$ & $0,4 \% \mathrm{c}$ \\
\hline$\delta$ juveniles & $5 / 57$ & $1 / 17$ & $1 / 10$ & $0 / 1$ & $10,1 \%$ & $8,2 \% \mathrm{~b}$ \\
\hline Total $\sigma^{\lambda}$ & $6 / 228$ & $1 / 72$ & $1 / 41$ & $0 / 5$ & $41,1 \%$ & $2,3 \% \mathrm{~b}$ \\
\hline TOTAL & 562 & 177 & 87 & 16 & $100 \%$ & $9,0 \%$ \\
\hline
\end{tabular}

Letras diferentes dentro de una misma columna muestran diferencias estadísticas significativas $(\mathrm{P} \leq 0,05)$

\section{Hallazgos histológicos}

En la evaluación de las biopsias extraídas de las vicuñas, sometidas a coloraciones específicas, para hongos (Figura 1), para bacterias (Figura 2) y para ácaros (Figura 3), se comprobó que las muestras de piel estaban libres de infecciones y ectoparásitos descartando la presencia de hongos, bacterias y ácaros. De esta manera, los resultados obtenidos en este trabajo descartaron que el agente etiológico causante de la "caspa" en vicuñas sea un microorganismo. También se descarta la alteración funcional de las glándulas sebáceas, éstas se observaron con normalidad en el microscopio.

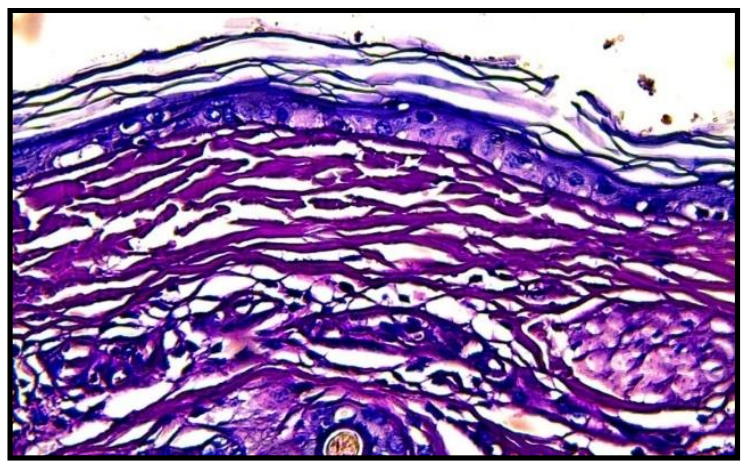

Figura 1. Microfotografía de la piel de vicuña con caspa libre de hongo. Coloración P.A.S. Vista a 400X. 


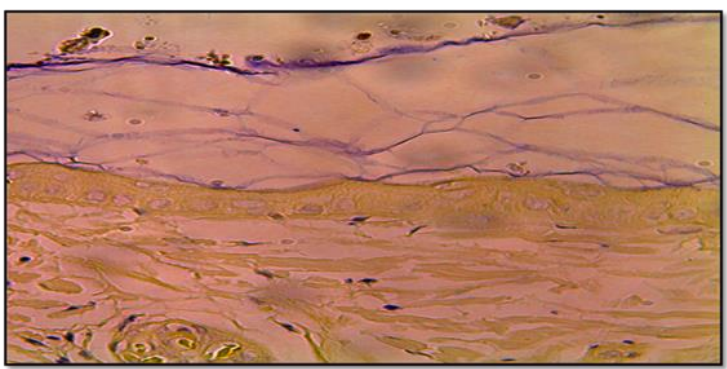

Figura 2. Microfotografía de la piel de vicuña libre de bacterias. Coloración GRAM. Vista a 400X.

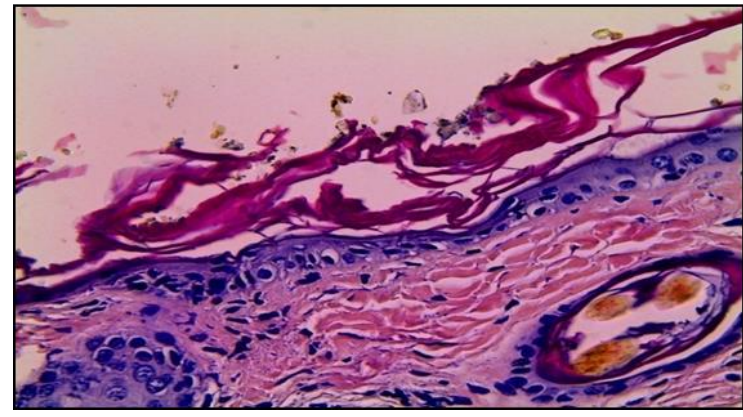

Figura 3. Microfotografía de la piel de vicuña libre de ácaros. Coloración H-E. Vista a 400X.

Por otro lado, se encontró alteraciones en el estrato córneo de la epidermis (Figura 4) detectándose hiperqueratosis de tipo paraqueratósica en un $86,7 \%$ y ortoqueratósica en 13,3\% (Tabla 3); mostrándose la paraqueratosis más persistente en comparación con la ortoqueratosis, indistintamente del sexo y edad.

Debemos tener en cuenta que el tejido de la piel está en constante división celular con el fin de mantener en óptimas condiciones el recambio celular y los cortes histológicos nos indican que dicha división celular está alterada; ya que el estrato córneo muestra la queratina en forma de láminas que se desprenden una de otras, dejando espacios vacíos y desiguales entre ellas (Figura 4); cuando normalmente deberían ser capas unidas entre sí, formadas por células muertas sin núcleo y cuyo citoplasma contiene escleroproteína rica en enlaces disulfuro (Junqueira y Carneiro, 2000).

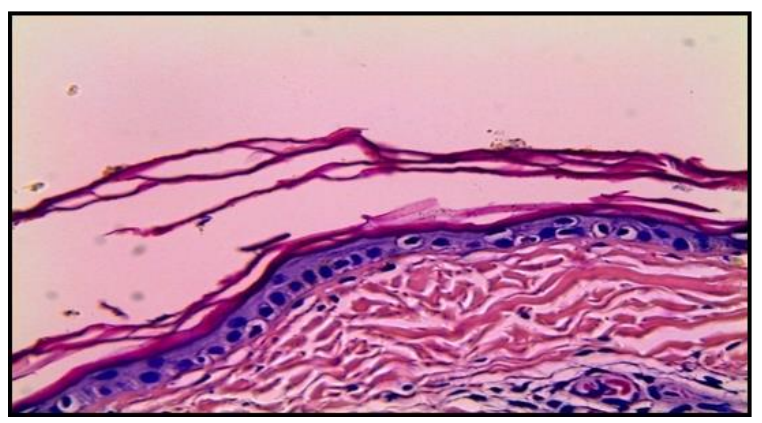

Figura 4. Microfotografía de la piel de vicuña afectada por la "caspa". Coloración H-E con aumento de 400X. A) Células de la capa córnea aún con núcleo (paraqueratosis). B). Células del estrato córneo sin núcleo (ortoqueratosis).

Tabla 3. Porcentaje de incidencia de paraqueratosis y ortoqueratosis.

\begin{tabular}{ccccccc}
\hline Hiperqueratosis & + adulta & + juvenil & Total de hembras & $\delta$ adulto & $\delta$ juvenil & Total de machos \\
\hline Paraqueratosis & $91,17 \mathrm{a}$ & $92,9 \mathrm{a}$ & $46,10 \mathrm{a}$ & $75,00 \mathrm{a}$ & $87,50 \mathrm{a}$ & $40,60 \mathrm{a}$ \\
Ortoqueratosis & $8,83 \mathrm{~b}$ & $7,10 \mathrm{~b}$ & $3,98 \mathrm{~b}$ & $25,00 \mathrm{~b}$ & $12,50 \mathrm{~b}$ & $9,39 \mathrm{~b}$ \\
\hline
\end{tabular}

$\overline{\mathrm{a}, \mathrm{b}}$. Letras diferentes dentro de una misma columna muestran diferencias estadísticas significativas $(\mathrm{P} \leq 0,05)$.

La presentación de ortoqueratosis nos estaría indicando que el desprendimiento de la capa córnea es mayor a su capacidad de síntesis; por lo que al evaluar el nivel de desprendimiento de la capa córnea, vemos que las hembras presentan preferentemente un abundante desprendimiento de la capa córnea, mientras los machos presentan niveles normales de desprendimiento aun cuando los niveles de desprendimiento abundante son significativamente superior (Tabla 4), lo que 
muestra que la hiperqueratosis es más severa en las hembras que en los machos.

La epidermis viene sufriendo un proceso inflamatorio crónico, que está alterando la epidermopoiesis (Jubb, y col., 1990). Coincidiendo con lo que menciona Radostits y col. (2000), acerca de que la paraqueratosis, puede deberse a la inflamación crónica inespecífica de la epidermis, a causa de la deficiencia dietética de proteínas, lípidos, zinc, cobre y/o vitamina $\mathrm{A}$; ya que la vitamina A actúa como un ligante entre lípidos y proteínas del epitelio apoyando la estabilización de la membrana (Mc. Dowell, 1989).

Tabla 4. Hiperqueratosis alteración de la capa córnea en la población.

\begin{tabular}{lccc} 
& \multicolumn{3}{c}{$\begin{array}{c}\text { Porcentaje de Presentación de los niveles de } \\
\text { desprendimiento de la capa córnea }\end{array}$} \\
Sexo/edad & Normal & Regular & Abundante \\
\hline क adulta & $0,00 \mathrm{c}$ & $14,70 \mathrm{~b}$ & $85,30 \mathrm{a}$ \\
o juvenil & $14,30 \mathrm{c}$ & $21,40 \mathrm{~b}$ & $64,30 \mathrm{a}$ \\
Total de 9 & $7,130 \mathrm{c}$ & $18,07 \mathrm{~b}$ & $74,80 \mathrm{a}$ \\
\hline Tadulto & $25,00 \mathrm{~b}$ & $25,00 \mathrm{~b}$ & $50,00 \mathrm{a}$ \\
† juvenil & $25,00 \mathrm{~b}$ & $37,50 \mathrm{a}$ & $37,50 \mathrm{a}$ \\
Total de $\delta$ & $26,70 \mathrm{c}$ & $33,30 \mathrm{~b}$ & $40,00 \mathrm{a}$ \\
\hline
\end{tabular}

a,b. Letras diferentes dentro de una misma columna muestran diferencias estadísticas significativas $(\mathrm{P} \leq 0,05)$.

Un bajo aporte de zinc, vitamina A y proteína en la dieta durante la gestación y la lactancia causa lesiones cutáneas, así como un cuadro de paraqueratosis, lo que coincide con los resultados del presente estudio, ya que la población más afectada fueron las hembras y los juveniles de ambos sexos, por lo que el estado del animal en la etapa reproductiva y en crecimiento tiene los mayores requerimientos nutricionales.

Por otro lado, se visualizó la presencia de acantosis en la capa basal de la epidermis en el $100 \%$ de las muestras (Figura 6); estando el 51,6\% de la población afectada por una hiperplasia abundante, tal como se observa en la Tabla 5; siendo las más afectadas las hembras con una hiperplasia abundante $(57,98 \%)$ en comparación con los machos que presentaron principalmente una hiperplasia moderada con $56,3 \%$ (Tabla 6).

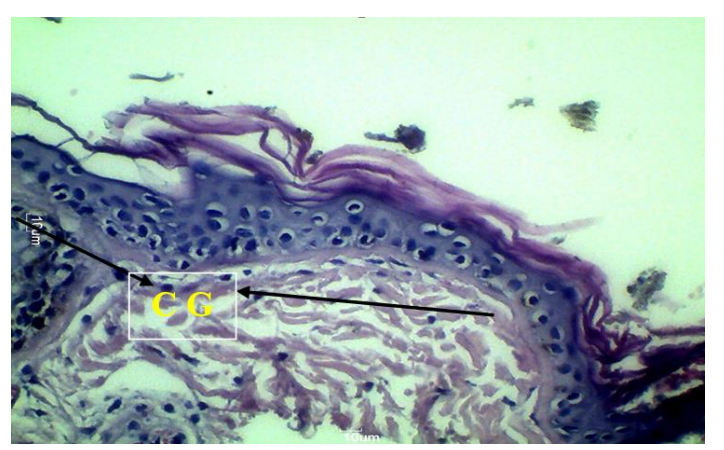

Figura 6. Microfotografía de piel de vicuña. Coloración H - E. Vista a 400X. C.G. Capa basal o germinativa. Se observa hiperplasia (ACANTOSIS).

Tabla 5. Porcentaje de la población afectada de acuerdo con el nivel de acantosis.

\begin{tabular}{lcc}
\hline & \# vicuñas & Porcentaje \\
\hline Población muestreada & 60 & $100 \%$ \\
Hiperplasia leve & 04 & $6,70 \% \mathrm{c}$ \\
Hiperplasia moderada & 25 & $41,70 \% \mathrm{~b}$ \\
Hiperplasia abundante & 31 & $51,60 \%$ a \\
\hline
\end{tabular}

Letras diferentes dentro de una misma columna muestran diferencias estadísticas significativas $(\mathrm{P} \leq 0,05)$.

Tabla 6. Niveles de acantosis en la población de acuerdo con la edad y sexo.

\begin{tabular}{cccc}
\hline Sexo/edad & $\begin{array}{c}\text { hiperplasia } \\
\text { leve }\end{array}$ & $\begin{array}{c}\text { hiperplasia } \\
\text { moderada }\end{array}$ & $\begin{array}{c}\text { hiperplasia } \\
\text { abundante }\end{array}$ \\
\hline Hembra adulta & $2,90 \mathrm{c}$ & $38,20 \mathrm{~b}$ & $58,80 \mathrm{a}$ \\
Hembra juvenil & $7,14 \mathrm{c}$ & $35,70 \mathrm{~b}$ & $57,14 \mathrm{a}$ \\
Total de hembras & $5,04 \mathrm{c}$ & $37,00 \mathrm{~b}$ & $57,98 \mathrm{a}$ \\
\hline Machos adultos & $25,00 \mathrm{~b}$ & $50,00 \mathrm{a}$ & $25,00 \mathrm{~b}$ \\
Machos juveniles & $12,50 \mathrm{c}$ & $63,00 \mathrm{a}$ & $25,00 \mathrm{~b}$ \\
Total de machos & $18,70 \mathrm{c}$ & $56,30 \mathrm{a}$ & $25.0 \mathrm{~b}$ \\
\hline
\end{tabular}

Letras diferentes dentro de una misma fila muestran diferencias estadísticas significativas $(\mathrm{P} \leq 0,05)$. 
Esto indica que el proceso inflamatorio crónico es más severo en las hembras; quienes llegaron a presentar los mayores daños en la epidermis, afectando inclusive la capa basal responsable de la constante renovación de la epidermis, en comparación con la población de machos. Esto es justificable porque son las hembras las que tienen los mayores requerimientos nutricionales por reproducción y/o crecimiento.

A ello se suma que la pradera altoandina está degradada, caracterizada con la desaparición de especies palatables a consecuencia del sobrepastoreo, inadecuado manejo de los pastizales y la competencia con otros animales. Es así que al observar la pradera nativa donde viven estas vicuñas, vemos una pradera pobre y totalmente sobrepastoreada, con escasa vegetación por prolongados periodos.

\section{CONCLUSIONES}

La prevalencia de "caspa" para la población de vicuñas en las zonas de amortiguamiento de la Reserva Nacional de Pampa Galeras es de 9,0\%; siendo la población de hembras adultas y juveniles las más afectadas, seguidas por lo machos juveniles; descartándose a cualquier microorganismo como agente etiológico. Sin embargo, se considera como agente causal de riesgo a: la mayor demanda nutricional, común en el crecimiento y/o reproducción en hembras, y a la deficiencia de nutrientes de riesgo tales como proteínas, ácidos grasos, vitamina $\mathrm{A}$, zinc y cobre.

\section{Conflictos de intereses}

Los autores firmantes del presente trabajo de investigación declaran no tener ningún potencial conflicto de interés personal o económico con otras personas $\mathrm{u}$ organizaciones que puedan influir indebidamente con el presente manuscrito.

\section{Contribuciones de los autores}

Preparación y ejecución: WT, MF; Desarrollo de la metodología: GP, MF; Concepción y diseño: GP, WT; Edición del artículo: MF, GP, WT; Supervisión del estudio: WT.

\section{LITERATURA CITADA}

- Alzola, R. (2002). Guía de estudio: Sistema Tegumentario. Curso de Histología, Embriología y Teratología. UNCPBA. Facultad de Ciencias Veterinarias. Argentina 3-12 p.

- Alzola, R. (2001). Guía de estudio: Técnicas histológicas. Curso de Histología, Embriología y Teratología (en línea). UNCPBA. Facultad de Ciencias Veterinarias. Departamento de Ciencias Biológicas, Argentina. Disponible en [18/09/2021]. http://www.slideshare.net/JoseMoi/tecnicashistológicas-11877628.

- Bustinza, A.V. (2001). La alpaca, conocimiento del gran potencial andino. 1ra Ed. Oficina de recursos del aprendizaje Sección publicaciones - UNA, Puno.

- Brack, A. (2010). La vicuña. Perú Ecológico. Disponible en [18/09/2021]. http://www.peruecologico.com.pe/econeg_vic una_masinfo.htm.

- CONACS. (2007). Ex Consejo Nacional de Camélidos Sudamericanos. Boletín Informativo Institucional 2007. Ministerio de Agricultura. Lima - Perú. 46p.

- Cotrina, V. (2009). Informe de la problemática de la "caspa" en vicuñas. Comunidad Campesina de Lucanas-Ayacucho. 30p.

- Gázquez, O.A. (1991). Patología Veterinaria 1ra ed. Editorial McGraw-Hill-Interamericana de España. 365 p.

- Jenkins, K., \& Kramer G. (1989). Influence of excess dietery copper on lipid compositions of calf tissues, J. Dairy Sci. 72, 2582-2591.

- Jubb, K.V., Kennedy, C., \& Palmer, N. (1990). Patología de los Animales Domésticos Tomo 1, 3ra. Edición. Editorial Agropecuaria Hemisferio Sur. Montevideo-Buenos Aires. $529 \mathrm{p}$.

- Junqueira, L., \& Carneiro, J. (2000). Histología básica. Masson S.A. España. 489 p.

- Lacolla, D.V., García, M.G., Hernández, C., \& Von Lawzewitsch, I. (2001). Sistema tegumentario de la vicuña (Vicugna vicugna). Histología. Facultad de. Ciencia Veterinarias. UNL Pam. Gral. Pico. La Pampa. 15-21p. 
- Mc. Dowell, L. (1992). Minerals in Animal and Human Nutrition. Academic Press Inc. USA. $524 \mathrm{p}$.

- Mc. Dowell, L. (1989). Vitamins in Animal Nutrition. Academic Press Inc. USA. 486 p.

- Palomino, M. (2001). Fisiología de la piel. Revista Peruana de Dermatología. 11(2). Disponible en [18/09/2021]. https://sisbib.unmsm.edu.pe/bvrevistas/dermat ologia/v11_n2/fisio_piel.htm
- $\quad$ Radostits, O., Gay, C., Blood, D., \& Hinchcliff, K. (2000). Medicina Veterinaria. Tratado de las enfermedades del ganado bovino, ovino, porcino, caprino y equino. Editorial Mc Graw Hill, Novena edición, Saskatoon-Canada. 1841, 1843 pp.

- Rodríguez, A. (1985). ¿Qué es el cuero? Curso sobre curtido al cromo. CIATEG- México.

- Trejo, W. (2013). Tecnología de cuero. Guía de práctica. Facultad de Zootecnia. Universidad Nacional Agraria La Molina. Perú. 60p. 